\title{
Development and Optimization of Venlafaxine Hydrochloride Sustained Release Triple Layer Tablets Adopting Quality by Design Approach
}

\author{
Shital Bhavin Butani \\ Department of Pharmaceutics and Pharmaceutical Technology, Institute of Pharmacy, Nirma University, Ahmedabad, India. \\ Email: shital_26@yahoo.com \\ Received April 15 ${ }^{\text {th }}, 2013$; revised May 25 ${ }^{\text {th }}, 2013$; accepted June $3^{\text {rd }}, 2013$ \\ Copyright (c) 2013 Shital Bhavin Butani. This is an open access article distributed under the Creative Commons Attribution License, \\ which permits unrestricted use, distribution, and reproduction in any medium, provided the original work is properly cited.
}

\begin{abstract}
Purpose: Venlafaxine hydrochloride sustained release formulation increases patient compliance by reducing frequency of administration and it also reduces side effects like nausea and vomiting. Hence the objective of present investigation was to develop triple layer sustained release tablets of venlafaxine $\mathrm{HCl}$ using xanthan gum or polyethylene oxide. Methods: The venlafaxine HCl $150 \mathrm{mg}$ sustained release tablets were prepared by wet granulation technique where drug was incorporated in middle layer with part of polymer. The barrier layers were composed of remaining polymer and other excipients. The granules and tablets were characterised. Optimized batches were also tested for drug release at different $\mathrm{pH}$ and in presence of ethanol, for kinetics of drug release and for water uptake/swelling. Results: Preliminary trials of monolayer tablet showed burst release due to high dose and solubility of venlafaxine $\mathrm{HCl}$ and hence triple layer tablets were developed. Granules of middle layer exhibited good flow properties. The comparative drug release to Effexor ${ }^{\circledR}$ XR capsule $150 \mathrm{mg}$ could be achieved by modulating the concentration of polymer and diluents in middle layer as well as in barrier layers. Higher amount of polyethylene oxide was required as compared to xanthan gum which may be due to high water uptake and poor gel strength of polyethylene oxide. The optimized formulations showed pH independent drug release as well as ethanol had no effect on drug release. Effexor ${ }^{\circledR}$ XR capsule and optimized batches followed Weibull kinetics for drug release. The radar diagrams showed the comparable drug release to innovator in both the optimized formulations but point to point correlation was observed in batch with xanthan gum. Conclusion: The layered matrix tablets formulated successfully using hydrophilic polymers, xanthan gum or polyethylene oxide, to sustain the release of highly soluble drug like venlafaxine $\mathrm{HCl}$.
\end{abstract}

Keywords: Venlafaxine HCl; Polyethylene Oxide; Xanthan Gum; Triple Layered Tablets

\section{Introduction}

Hydrophilic polymer matrix systems are first choice of researchers to modify the drug release as they are highly flexibile to obtain a desirable drug release profile [1]. Matrix tablets are easy to formulate and optimized to control the release of drug and thus maintaining a therapeutically effective concentration in the systemic circulation for quire a long time which results in to reduced dosing frequency and improving patient compliance [2,3]. Hypromellose, sodium carboxymethylcellulose, xanthan gum, guar gum, polyvinyl alcohol, polyethylene oxide and carbopols ${ }^{\circledR}$ are a few examples that have been extensively evaluated as hydrophilic polymers to modify release of variety of drugs i.e. poorly soluble to highly soluble. Formulation of layered tablets known as geo- metric $^{\circledR}$ tablets can be explored to design the drug release profile as per the requirement and to prevent burst release specially with highly soluble drugs like venlafaxine $\mathrm{HCl}$. Two or three layered tablets can be formulated where drug may be in all layers or only in middle layer [4-6].

Due to higher aqueous solubility of drug, it is a challenge to formulate extended release tablets. Many researchers explored xanthan gum alone or in combination with other hydrophilic polymer as a matrixing agent for controlling the drug release [7-12]. It's the only microbial polysaccharide produce on large scale which is non-toxic in nature and swells when comes in contact with gastric fluid. It is an excellent release retardant material and has been used for development of matrix tablets of many model drugs like prednisolone and in- 
domethacin [13,14].

Polyethylene oxide (PEO) is water soluble resin, available in different grades under the brand name of Polyox ${ }^{\circledR}$. These were explored in melt granulation technology due to lower melting points. Further more high viscosity grades showed matrixing properties similar to hypromellose and hence could be explored for formulation of matrix tablets [15-17]. They are available in direct compression grade with good flow properties. They are sensitive to oxidation and hence contained antioxidant. These polymers are biocompatible and various grades can be used together to get required properties which attract the researcher to explore them for verity of uses. These have been used for controlling the drug release by few scientists [18-20].

Venlafaxine $\mathrm{HCl}$ is an antidepressant which structurally differs from other class of antidepressants [21]. Hydrochloride salt of venlafaxine is having high aqueous solubility $(572 \mathrm{mg} / \mathrm{ml})$ and short biological half-life (5 \pm $2 \mathrm{~h}$ ) which make it, a suitable candidate for the development of once a day formulation. It is difficult to administer the drug to psychotic patient and formulation of extended release dosage form reduces the frequency of administration. Furthermore, it is reported that the extended release formulation of venlafaxine $\mathrm{HCl}$ was tolerated well by the patients without side effects like nausea and dizziness [22]. Thus it is logical to develop once a day formulation for improved patient compliance and to reduce side effects.

The objective of the current study was to elucidate the release of venlafaxine $\mathrm{HCl}$ using xanthan gum or polyethylene oxide as matrixing agents. Effexor ${ }^{\circledR}$ XR Capsules $150 \mathrm{mg}$ manufactured by Wyeth Pharmaceuticals Inc. was used as reference product. Two formulations were developed using systematic quality by design approach, having comparative drug release profile with innovator product.

\section{Materials and Methods}

\subsection{Materials}

Venlafaxine HCl (D (v, 0.1) < $2.79 \mu$, D (v, 0.5) < 10.04 $\mu$ and $\mathrm{D}(\mathrm{v}, 0.9)<43.98 \mu)$ was received as a gift sample from Cadila Healthcare Ltd., Ankleshwar. Xanthan gum was obtained from Alok International, Mumbai. Polyethylence oxides (Polyox WSR 303) were obtained from Union Carbide, USA. Microcrystalline cellulose (Avicel PH 101, FMC Biopolymer, USA) and lactose monohydrate (Pharmatose DCL 21, DMV International Inc., The Netherlands) were used as received. Magnesium stearate was purchased from Laser Chemicals, Ahmedabad. Effexor $^{\circledR}$ XR Capsules 150 mg (Wyeth Pharmaceuticals Inc., Expiry date: 04/2011) was used as a reference product.

\subsection{Methods}

\subsubsection{Monolayer Tablets}

Drug and polymer in 1:1 ratio was used for formulation of monolayer tablet (Batches X1, X2 and P1). The ingredients were passed through mesh 30 \# and dry blended. The dry mix was granulated with water and the wet mass was dried in a tray dryer at $60^{\circ} \mathrm{C} \pm 5^{\circ} \mathrm{C}$ temperature till percent loss on drying was below $3 \%$. The blend was then sieved through mesh 24 \#, lubricated and compressed in to tablets. The tablets were evaluated for crushing strength, thickness, friability, weight variation and in vitro drug release.

\subsubsection{Triple Layer Tablets}

Triple layer tablets were prepared by putting drug free barrier layers on either side of the middle layer. The middle layer contained venlafaxine $\mathrm{HCl}$, part of polymer and microcrystalline cellulose (Avicel PH 101). These granules were prepared same as monolayer tablets and formed the core layer (batches X3 to X8, Table 1). The barrier layer consists of part of polymer, diluent and magnesium stearate. Three layered tablets were compressed using 16 station rotary tablet press (Karnavati Engineering Ltd., Mehsana, India) and evaluated as above.

Seven batches (P2 to P8) were prepared as per simplex lattice design for optimization of polyethylene oxide concentration to obtain drug release profile similar to reference product (Table 2). The linear interactive full

Table 1. Composition of venlafaxine $\mathrm{HCl}$ tablets containing xanthan gum.

\begin{tabular}{|c|c|c|c|c|c|c|c|c|}
\hline \multirow{2}{*}{$\begin{array}{l}\text { Ingredients } \\
\text { (mg) }\end{array}$} & \multicolumn{8}{|c|}{ Batch Code } \\
\hline & $\mathrm{X} 1$ & $\mathrm{X} 2$ & X3 & $\mathrm{X} 4$ & X5 & X6 & $\mathrm{X7}$ & X8 \\
\hline \multicolumn{9}{|c|}{ Intragranular/Middle Layer Composition } \\
\hline Venlafaxine $\mathrm{HCl}^{* *}$ & 169.8 & 169.8 & 169.8 & 169.8 & 169.8 & 169.8 & 169.8 & 169.8 \\
\hline Xanthan gum & 42.5 & 63.7 & 42.5 & 42.5 & 22.5 & 42.5 & 42.5 & 42.5 \\
\hline Avicel PH 101 & 53.0 & 53.0 & 53.0 & 53.0 & 53.0 & 53.0 & 53.0 & 53.0 \\
\hline \multicolumn{9}{|c|}{ Extragranular/Barrier Layer Composition } \\
\hline Xanthan gum & 127.4 & 191.0 & 127.4 & 127.4 & 127.4 & 85.0 & 75.0 & 65.0 \\
\hline Avicel PH 101 & - & - & 50.0 & - & - & - & - & - \\
\hline $\begin{array}{l}\text { Pharmatose } \\
\text { DCL } 11\end{array}$ & - & - & - & 50.0 & 50.4 & 50.2 & 60.2 & 70.2 \\
\hline
\end{tabular}

*Each batch contains $7.5 \mathrm{mg}$ of magnesium stearate; ${ }^{* * *}$ Venlafaxine $\mathrm{HCl}$ $168.9 \mathrm{mg}$ is equivalent to venlafaxine $150 \mathrm{mg}$. 
Table 2. Composition of venlafaxine $\mathrm{HCl}$ tablets containing polyethylene oxide.

\begin{tabular}{|c|c|c|c|c|c|c|c|c|}
\hline \multirow{2}{*}{$\begin{array}{l}\text { Ingredients } \\
\text { (mg) }\end{array}$} & \multicolumn{8}{|c|}{ Batch code } \\
\hline & P1 & P2 & P3 & $\mathbf{P 4}$ & P5 & P6 & P7 & P8 \\
\hline \multicolumn{9}{|c|}{ Core layer } \\
\hline $\begin{array}{l}\text { Venlafaxine } \\
\mathrm{HCl}^{* *}\end{array}$ & 169.8 & 169.8 & 169.8 & 169.8 & 169.8 & 169.8 & 169.8 & 169.8 \\
\hline $\begin{array}{c}\text { Polyox WSR } \\
303\end{array}$ & 42.0 & $\begin{array}{c}42.0 \\
(0)\end{array}$ & $\begin{array}{l}42.0 \\
(0)\end{array}$ & $\begin{array}{c}62.0 \\
(1)\end{array}$ & $\begin{array}{c}42.0 \\
(0)\end{array}$ & $\begin{array}{l}52.0 \\
(0.5)\end{array}$ & $\begin{array}{l}52.0 \\
(0.5)\end{array}$ & $\begin{array}{c}48.7 \\
(0.33)\end{array}$ \\
\hline Avicel PH 101 & 52.3 & 53.0 & 53.0 & 53.0 & 53.0 & 53.0 & 53.0 & 53.0 \\
\hline \multicolumn{9}{|c|}{ Barrier layers } \\
\hline $\begin{array}{c}\text { Polyox WSR } \\
303\end{array}$ & 75.0 & $\begin{array}{c}110.0 \\
(1)\end{array}$ & $\begin{array}{c}80.0 \\
(0)\end{array}$ & $\begin{array}{c}80.0 \\
(0)\end{array}$ & $\begin{array}{l}95.0 \\
(0.5)\end{array}$ & $\begin{array}{c}80.0 \\
(0)\end{array}$ & $\begin{array}{l}95.0 \\
(0.5)\end{array}$ & $\begin{array}{c}90.0 \\
(0.33)\end{array}$ \\
\hline $\begin{array}{l}\text { Pharmatose } \\
\text { DCL } 11\end{array}$ & 60.0 & $\begin{array}{c}40.0 \\
(0)\end{array}$ & $\begin{array}{c}60.0 \\
(1)\end{array}$ & $\begin{array}{c}40.0 \\
(0)\end{array}$ & $\begin{array}{l}50.0 \\
(0.5)\end{array}$ & $\begin{array}{l}50.0 \\
(0.5)\end{array}$ & $\begin{array}{l}40.0 \\
(0)\end{array}$ & $\begin{array}{c}46.7 \\
(0.33)\end{array}$ \\
\hline
\end{tabular}

*Each tablet contained $1.5 \%$ magnesium stearate. The parenthesis shows the transformed value of independent variables; ${ }^{* *}$ Venlafaxine $\mathrm{HCl} 168.9 \mathrm{mg}$ is equivalent to venlafaxine $150 \mathrm{mg}$.

model is shown below:

$$
Y=b_{1} X_{1}+b_{2} X_{2}+b_{3} X_{3}+b_{12} X_{1} X_{2}+b_{13} X_{1} X_{3}+b_{23} X_{2} X_{3}
$$

where $Y$ is the dependent variable; $b_{i}$ is the estimated coefficient for the factor $X_{i}$ Three way interactions were suppressed to perform regression analysis. The reduced model was developed by eliminating insignificant terms $(\mathrm{P}>0.05)$ from the full model. The dependent variables were the percentage drug dissolved at 1, 4, 10 and $24 \mathrm{~h}$.

\subsection{In Vitro Dissolution Studies}

In vitro drug release study $(\mathrm{n}=3)$ was carried out in USP apparatus I (Electrolab TDT 06-T, Mumbai, India) in 900 $\mathrm{mL}$ of distilled water at $37^{\circ} \mathrm{C} \pm 0.5^{\circ} \mathrm{C}$. Five $\mathrm{mL}$ samples were pulled at predetermined times. The drug solution was replaced with equal volume of distilled water. The samples were diluted with water and analyzed at $226 \mathrm{~nm}$ using UV visible spectrophotometer (Shimadzu-1700, Japan). The dissolution study was also performed for reference product (Effexor ${ }^{\circledR}$ XR Capsules $150 \mathrm{mg}$ ).

\section{Evaluation of Optimized Batches}

\subsection{Drug Release at Different pH}

The dissolution study of the optimized batches and reference was also performed in $0.1 \mathrm{~N} \mathrm{HCl}$, phosphate buffer (pH 6.8). The effect of ethanol on drug release was also evaluated by replacing $10 \%$ distilled water with ethanol.

\subsection{Drug Release Kinetics}

In order to investigate the kinetics of drug release from matrix tablets, the data of in vitro drug release of optimized batches were fitted to different models [23-27]. The software was developed using FORTRAN language for zero order, first order, Higuchi, Hixson-Crowell, Korsmeyer-Peppas and Weibull models. The Fisher's ratio (F) was employed to select the most appropriate kinetic model. The model selection was done by the method of Bamba [28].

\subsection{Water Uptake and Swelling Study}

Tablet of Batches X7 and P7 were subjected to water uptake and swelling studies [29]. The tablets were kept in a beaker containing $100 \mathrm{~mL}$ distilled water maintained at $37^{\circ} \mathrm{C} \pm 2^{\circ} \mathrm{C}$. At selected time points, the tablets were withdrawn, wiped with tissue paper and weighed. The percent water uptake by the tablet was calculated using the following formula:

$$
\text { Percentage water uptake }=100 *\left[\left(W_{t}-W\right)_{0} / W_{0}\right]
$$

where $W_{t}$ is weight of tablet at time $t$ and $W_{0}$ is initial weight of the tablet. Axial and radial swelling was also calculated using thickness and diameter instead of weight in above formula.

\subsection{The Radar Graphs}

In the dissolution study, higher or lower \% drug release, than a target value is permitted up to a certain limit. Shah et al. proposed that the maximum difference can be $10 \%$ $\left(f_{2}=50\right)$ for establishing similarity in dissolution [30]. The dissolution profile of reference product (Effexor ${ }^{\circledR}$ XR $150 \mathrm{mg}$ ) was considered as ideal release pattern. The percent drug release of reference product will get a score of five (ideal) on a scale of zero to ten. The lowest and highest permissible \% of drug release will get a score of zero and ten respectively. The scores of optimized batches (X7 and P7) were calculated at each dissolution time point.

$$
\text { Score }=5+\left\{\left(\% T_{t}-\% R_{t}\right) / 2\right\}
$$

where $\% T_{t}$ is percentage drug released from test batch while $\% R_{t}$ is percentage drug released from reference product at the same time.

\section{Results and Discussion}

The present study was aimed to develop extended release matrix tablets of venlafaxine $\mathrm{HCl}$ using hydrophilic polymer. Effexor ${ }^{\circledR}$ XR $150 \mathrm{mg}$ capsule was the innovators product containing coated pellets. The dissolution of the reference product was targeted for the developed venlafaxine $\mathrm{HCl}$ matrix tablets. Distilled water was used as primary dissolution media as food and drug admini- 
stration (FDA) endorses the use of it as a dissolution medium for the generic version of venlafaxine $\mathrm{HCl}$. Dissolution profile of Effexor ${ }^{\circledR}$ XR capsule is shown in Figure 1 which reveals that the drug release was less than 25\% in first $2 \mathrm{~h}$. The slower initial drug release indicates that the pellets of reference product might be coated with water insoluble coating material. Two points need to be kept in mind before starting the development of generic version for Effexor ${ }^{\circledR}$ XR Capsules. These are higher aqueous solubility of venlafaxine $\mathrm{HCl}(572 \mathrm{mg} / \mathrm{mL})$ and the pellets are coated with water insoluble material like ethyl cellulose which is filled in a capsule as a brand formulation. These indicate that higher solubility gives higher drug release at initial time points which need to be reduced by coating or formulation of layered tablets to match the drug release of developed formulation with reference product.

Direct compression method was not feasible due to poor flow properties of drug. The lubricated blends were prepared (Batch X1 to X8) and found to have good flow properties in terms of angle of repose (23 $23^{\circ}$ to $\left.26^{\circ}\right)$, Carr's index (16\% to $19 \%)$ and Hausner ratio (1.16 to 1.21$)$. Monolayer tablets, Batches X1 and X2 were prepared using 1:1 and 1:1.5 drug to polymer ratio respectively (Table 1). The standard concave tablets showed acceptable crushing strength (>6 kp) and friability $(<1 \%)$. The problems of weight variation and content variation were not observed. Batches X1 and X2 showed burst drug release as expected as compared to reference product but he drug release was slower at later time points (Figure 1). This indicates that the required release profile could not be achieved by only altering the concentration of xanthan gum.

The problem of fast drug release in earlier phase of dissolution testing can be resolved either by coating the matrix tablet or by formulating layered tablets. Multi-

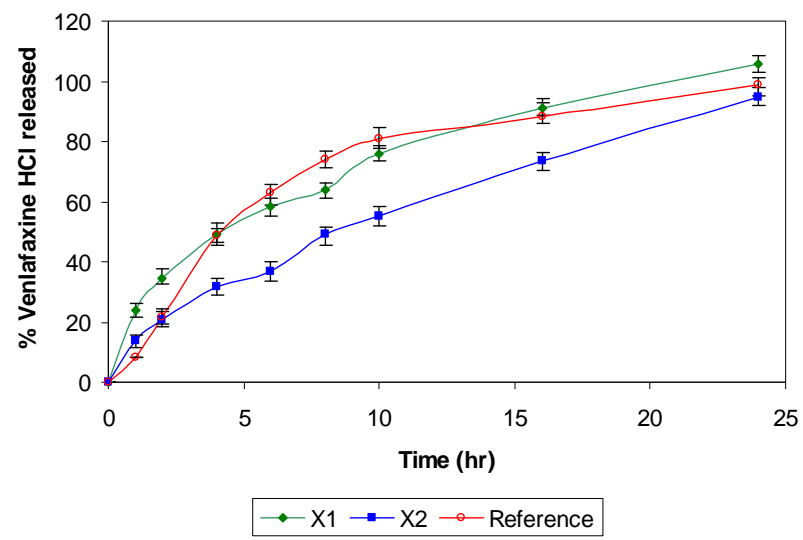

Figure 1. Comparative drug release profiles of monolayer tablet of venlafaxine $\mathrm{HCl} 150 \mathrm{mg}$ containing xanthan gum (Batches X1 and X2). layer tablets have been developed by scientists for obtaining better control of drug release from hydrophilic polymeric systems $[6,31,32]$. The surface area exposed to the dissolution medium is reduced in layered tablets and hence the burst drug release can be arrested. Batches X3 and $\mathrm{X} 4$ were formulated as triple layer tablets where drug, part of polymer and part of diluents were granulated and formed the middle layer. The barrier layers were made up of remaining part of polymer, diluent and lubricant (Table 1). Burst release was not observed and both the batches showed slower drug release after $2 \mathrm{~h}$ then required (Figure 2). Thus there is need to increase the drug release at later time points without affecting the initial release. This could be achieved either by reducing the concentration of polymer in core layer and barrier layers or by increasing the concentration of Pharmatose DCL, a water soluble diluent to increase number of pore forms in barrier layers. Hence Batches X5 to X8 were prepared as shown in Table 1. Batch X7 showed drug release comparable to the Effexor ${ }^{\circledR}$ XR capsules $\left(f_{2}=74\right)$ and hence was selected as optimized batch with xanthan gum (Figure 3).

Batch P1 was prepared using drug to Polyox WSR 303 in ratio of 1:1 respectively and drug release profile was

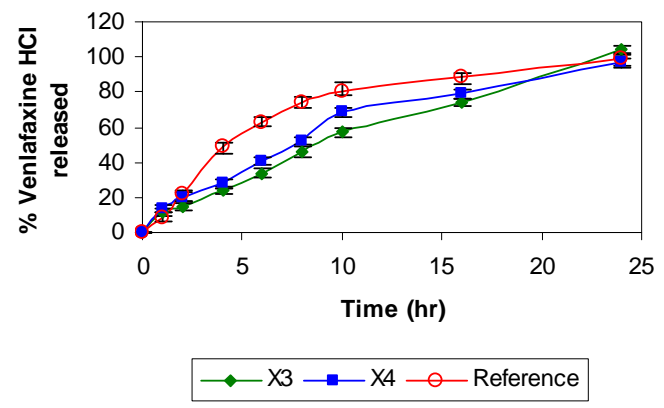

Figure 2. Comparative drug release profiles of triple layer tablets of venlafaxine $\mathrm{HCl} 150 \mathrm{mg}$ containing xanthan gum (Batches X3 and X4).

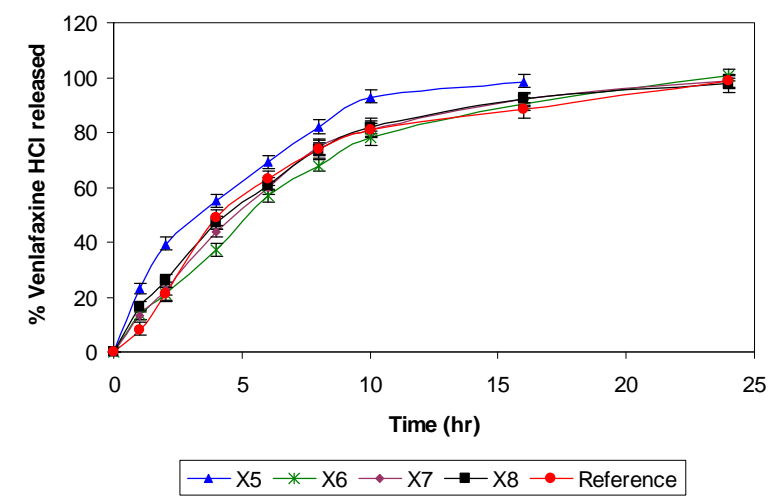

Figure 3. Comparative drug release profiles of triple layer tablets of venlafaxine $\mathrm{HCl} 150 \mathrm{mg}$ containing xanthan gum (Batches X5 to X8). 
compared with reference product and with Batch X1 (Figure 4). Matrix tablet containing polyox WSR 303 showed faster drug release as compared to xanthan gum. This may be due to fast hydrating nature with poor gel strength of Polyox WSR 303. Hence, higher amount of it may be required to formulate the matrix tablets to achieve drug release profile similar to Batch X7. The percentages of polymer in barrier layers, in middle layer as well as amount of diluent are important variable affecting the drug release. It was decided to use mixture design to optimize the formulation. Hence the amount of Polyox WSR 303 ( $X_{1}, 80 \mathrm{mg}$ to $110 \mathrm{mg}$ ) and of Pharmatose DCL $11\left(X_{2}, 40 \mathrm{mg}\right.$ to $\left.60 \mathrm{mg}\right)$ in barrier layers and the amount of Polyox WSR 303 ( $X_{3}, 42 \mathrm{mg}$ to $62 \mathrm{mg}$ ) in core layer were selected as independent variables in the Simplex lattice design (Table 2). The formulated batches showed acceptable granules and tablet characteristics. The drug release profiles are shown in Figure 5. The values of similarity factor $f_{2}$ were $65,52,61,70,53,72$ and 67 respectively for Batches P2 to P8. The drug release at different time $\left(Y_{1}, Y_{4}, Y_{10}\right.$ and $\left.Y_{24}\right)$ was selected as de-

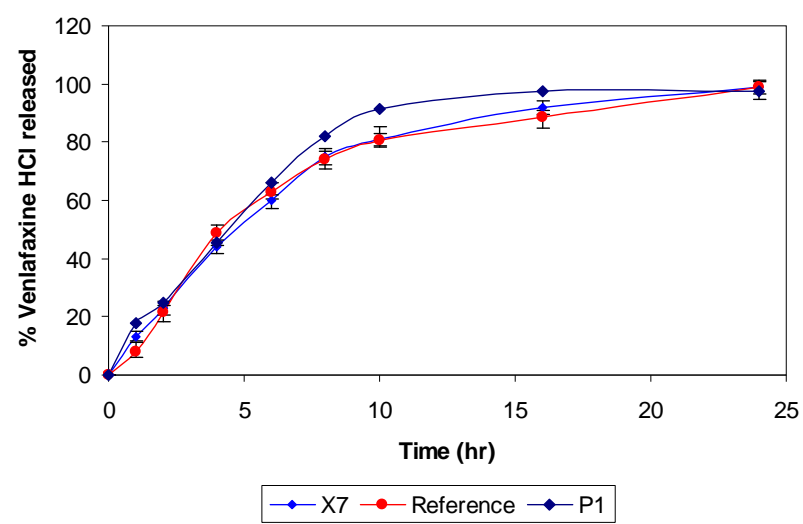

Figure 4. Comparative drug release profiles of venlafaxine HCl tablets $150 \mathrm{mg}$ containing xanthan gum and polyethylene oxide (Batches X7 and P1).

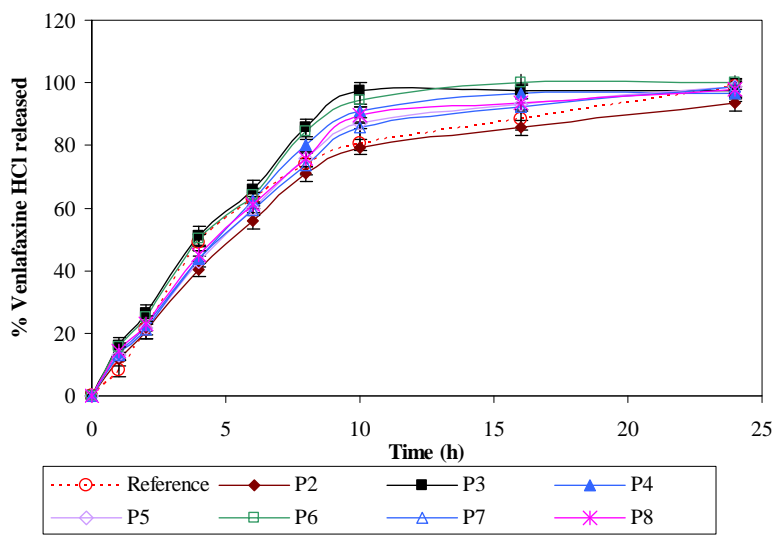

Figure 5. Comparative drug release profiles of simplex batches containing polyethylene oxide (Batches $\mathrm{P} 2$ and $\mathbf{P 8}$ ). pendent variables. The low and high values of independent variable were transformed as 0 and 1 respectively. The reduced models containing significant terms are shown below:

$$
\begin{gathered}
Y_{1}=12.51 X_{1}+15.07 X_{2}+13.95 X_{3} \\
Y_{4}=39.40 X_{1}+48.87 X_{2}+42.60 X_{3}+33.49 X_{2} X_{3} \\
Y_{10}=79.08 X_{1}+93.94 X_{2}+88.08 X_{3}+40.63 X_{2} X_{3} \\
Y_{24}=95.92 X_{1}+98.48 X_{2}+98.36 X_{3}
\end{gathered}
$$

The check-point Batch P9 $\left(X_{1}=0.6, X_{2}=0.2\right.$ and $X_{3}=$ $0.2)$ was prepared to validate models (Equations (4)-(7)). The experimental values of $Y_{1}, Y_{4}, Y_{10}$ and $Y_{24}$ were 11.6, 41.1, 82.6 and 99.5 respectively. The computed values were 13.4, 43.3, 85.5 and 96.9. Good agreement between observed and predicted values shows predictive capability of equations. Batch P7 was selected as optimized batch as it showed highest similarity $\left(f_{2}=72\right)$ with the reference product.

The dissolution data of the reference product and the test formulations (Batches X7 and P7) in $0.1 \mathrm{~N} \mathrm{HCl}$ and phosphate buffer ( $\mathrm{pH}$ 6.8) are depicted in Figure 6. The optimized batches showed similar dissolution in acidic and basic dissolution media. The solubility, swelling and gelling tendencies of major ingredients in tablets may have remained same in the acidic and basic medium. Both the polymers showed $\mathrm{pH}$ independent drug release.

The FDA has suggested the testing of modified release dosage forms in dissolution media containing ethanol. The FDA mentions that the potentially fatal interaction of a modified release system might be observed on consumption of alcohol which results in impairment of the formulation and dose dumping [33,34]. Ten percent ethanol, typical of those found in alcoholic beverages, was included in dissolution media (distilled water). The dissolution study of Batches X7 and P7 were performed

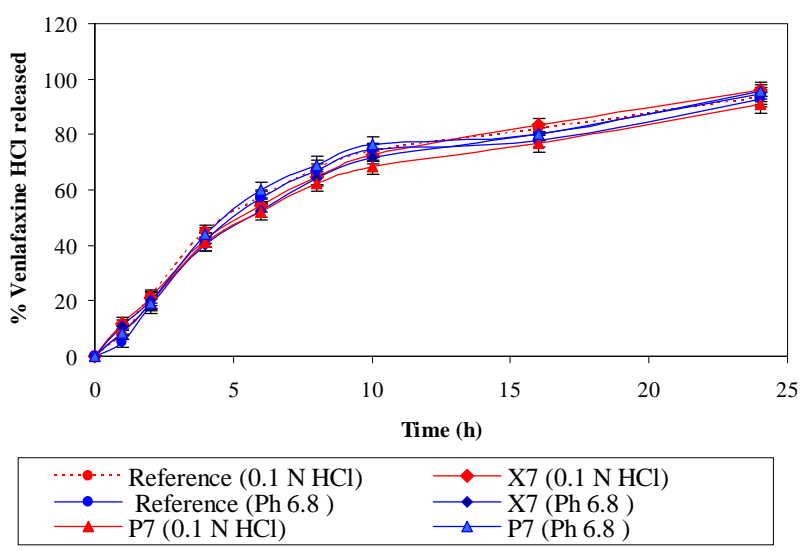

Figure 6. Comparative dissolution profiles of reference and optimized batches in $0.1 \mathrm{~N} \mathrm{HCl}$ and phosphate buffer (pH 6.8). 
using same dissolution conditions with and without ethanol. Batches X7 and P7 showed similarity factor $\left(f_{2}\right)$, 92 and 85, respectively with and without ethanol. The matrix of xanthan gum and polyethylene oxide did not collapse in either water or in hydroalcoholic medium. Thus we can conclude that both the developed formulations are robust and are safe even if alcohol is consumed.

The goodness of fit test was used to determine the mechanism of drug release. A FORTRAN software, developed in house, was used to fit to zero-order, first-order, Higuchi, Hixson-Crowell, Korsmeyer-Peppas and Weibull model. The drug release data of Effexor ${ }^{\circledR}$ XR capsules, Batches X7 and P7 were subjected to data treatment. The least value of sum of square and Fischer's ratio were used to select the most appropriate kinetic model. The reference product also followed both higuchi and weibull model for drug release. The Weibull model best explained the drug release as the Fisher's ratio was less than 7 and correlation coefficient was above 0.99 for the Batches X7 to P7 (Table 3).

Figure 7 shows the average value of water uptake of the optimum batches (X7 and P7). The study showed that water uptake by Batch P7 was higher as compared to the Batch X7. The Polyox WSR 303 is fast hydrating polymer and it take up high amount of water. Tablets containing Polyox WSR 303 showed higher water uptake as compared to tablets containing xanthan gum. The axial swelling is more predominant as compared to radial swelling with both the polymers.

The radar diagrams of Batches X7 and P7 are shown in Figure 8. The dissolution pull times are shown on the periphery of radar diagrams. The outer surface of radar graphs shows highest score (ten) while the centre shows lowest score (zero). Ideally, all the data points should fall on score line of five, i.e. in the middle of radar diagram. The radar diagrams of Batch X7 shows that most of the data points fall on or near the ideal line while the data of Batch P7 shows more deviation. The sums of absolute value of difference between reference and test at all time points were 8.7 and 22.7 respectively for Batches X7 and P7. The low values of computed difference quantitatively show the similarity. The value of sum can vary between 0 (ideal) and 40 (borderline case). The radar diagram can be used to show the comparative drug release profiles in a novel way. We can conclude that Batch X7 shows point

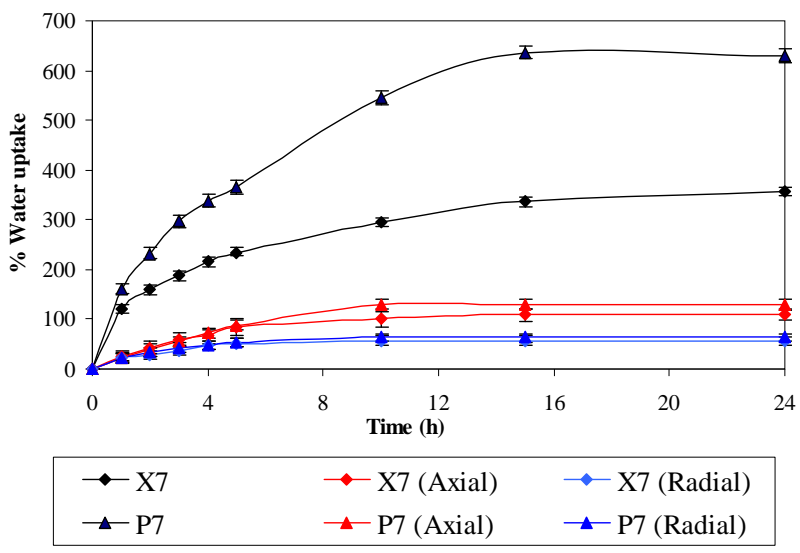

Figure 7. Swelling study of optimized batches.
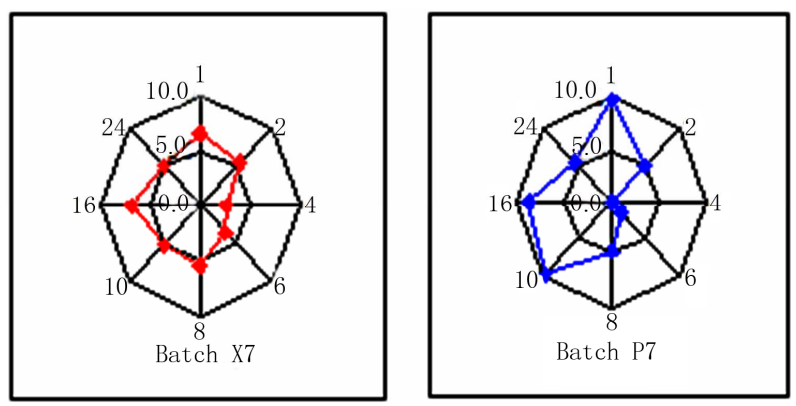

Figure 8. Radar diagrams of optimized batches.

Table 3. Model fitting data of optimized batches.

\begin{tabular}{|c|c|c|c|c|c|c|c|}
\hline Batch & Parameters & Zero Order & First Order & Higuchi & Hixson-Crowell & Korsmeyer-Peppas & Weibull \\
\hline & SSR & 2410.81 & 106.76 & 716.35 & 644.80 & 2791.56 & 119.55 \\
\hline \multirow[t]{3}{*}{ Effexor $^{\circledR}$ XR Capsules } & F ratio & 344.40 & 15.25 & 102.34 & 92.11 & 465.26 & 19.92 \\
\hline & $r^{2}$ & 0.7703 & 0.9758 & 0.9317 & 0.9621 & 0.8965 & 0.9836 \\
\hline & SSR & 2131.36 & 131.65 & 547.70 & 410.32 & 1337.33 & 15.46 \\
\hline \multirow[t]{3}{*}{$\mathrm{X} 7$} & F ratio & 304.48 & 18.81 & 78.24 & 58.62 & 222.89 & 2.58 \\
\hline & $r^{2}$ & 0.7933 & 0.9940 & 0.9469 & 0.9716 & 0.9463 & 0.9974 \\
\hline & SSR & 2270.15 & 205.71 & 648.94 & 448.94 & 1528.22 & 37.74 \\
\hline \multirow[t]{2}{*}{ P7 } & F ratio & 324.31 & 29.39 & 92.71 & 64.13 & 254.70 & 6.29 \\
\hline & $r^{2}$ & 0.7870 & 0.9888 & 0.9391 & 0.9630 & 0.9438 & 0.9933 \\
\hline
\end{tabular}

SSR: Sum of square of residuals; F ratio: Fisher's ratio; $\mathrm{r}^{2}$ : Correlation coefficient. 
to point correlation with reference product.

\section{Conclusion}

High aqueous solubility of venlafaxine $\mathrm{HCl}$ makes it difficult to formulate uncoated monolayer tablet to develop generic version of Effexor ${ }^{\circledR}$ XR Capsules $150 \mathrm{mg}$. Triple layer tablets were developed by varying amount of important variables and using quality by design approach. Xanthan gum as well as polyethylene oxide was used to formulate matrix tablets with comparable drug release to Effexor $^{\circledR}$ XR $150 \mathrm{mg}$ capsules. The drug release from both the optimized batches was explained by Weibull model. The optimized formulations showed $\mathrm{pH}$ independent release and the dissolution pattern was unaltered in presence of $10 \%$ ethanolic solution. The production rate of triple layer tablets is higher then that of coated pellets and hence the developed formulations appear to be an attractive option to industry to consider for bioequivalence study. A drug release profile similar to that of the reference product (Effexor ${ }^{(\mathbb{}}$ XR Capsule) was achieved by adopting systemic formulation approach.

\section{Acknowledgements}

The authors are thankful to Gattefosse, France and BASF, Germany for providing gift samples.

\section{REFERENCES}

[1] D. A. Alderman, "A Review of Cellulose Ethers in Hydrophilic Matrices for Oral Controlled-Release Dosage Forms," International Journal of Pharmaceutics and Technology Production Manufacturing, Vol. 5, No. 3, 1984, pp. 1-9.

[2] S. Anurag and P. Ramesh, "Design of Controlled Release Delivery Systems Using a Modified Pharmacokinetic Approach: A Case Study for Drugs Having a Short Elimination Half-Life and a Narrow Therapeutic Index," International Journal of Pharmaceutics, Vol. 261, No. 1-2, 2003, pp. 27-41. doi:10.1016/S0378-5173(03)00267-9

[3] N. Najib and M. S. Suleiman, "The Kinetics of Drug Release from Ethyl Cellulose Solid Dispersions,” Drug Development and Industrial Pharmacy, Vol. 11, No. 12, 1985, pp. 2169-2181. doi:10.3109/03639048509087779

[4] M. R. Siahi, M. B. Jalali, F. Monajjemzadeh, F. Ghaffari and S. Azarmi, "Design and Evaluation of 1- and 3-Layer Matrices of Verapamil Hydrochloride for Sustaining Its Release,” AAPS PharmSciTech, Vol. 4, No. 4, 2005, Article No. 77.

[5] U. Conte and L. Meggi, "Multi-Layer Tablets as Drug Delivery Devices: Geomatrix ${ }^{\circledR}$ Technology,” Pharmaceutical Technology Europe, Vol. 1, No. 2, 1998, pp. 1825.

[6] S. Bariya and M. Gohel, “Advanced Formulation Design of Venlafaxine Hydrochloride Coated and Triple Layer
Tablets Containing Hypromellose," Pharmaceutical Development and Technology, Vol. 14, No. 6, 2009, pp. 650-658.

[7] S. H. Bariya and M. C. Gohel, "Formulation of TripleLayer Matrix Tablets of Venlafaxine $\mathrm{HCl}$ Using Xanthan Gum,” AAPS PharmSciTech, Vol. 10, No. 2, 2009, pp. 624-630. doi:10.1208/s12249-009-9244-z

[8] N. Billa and K. H. Yuen, "Formulation Variables Affecting Drug Release from Xanthan Gum Matrices at Laboratory Scale and Pilot Scale,” AAPS PharmSciTech, Vol. 1, No. 4, 2000, pp. 35-42. doi:10.1208/pt010430

[9] A. Lachke, "Xanthan-A Versatile Gum,” Resonance, Vol. 9, No. 10, 2004, pp. 25-33. doi:10.1007/BF02834866

[10] M. F. Lu, L. Woodward and S. Borodkin, "Xanthan Gum and Alginate Based Controlled Release Theophylline Formulations," Drug Development of Industrial Pharmacy, Vol. 17, No. 14, 1991, pp. 1987-2004. doi:10.3109/03639049109048063

[11] D. L. Munday and P. J. Cox, "Compressed Xanthan and Karaya Gum Matrices: Hydration, Erosion and Drug Release Mechanisms," International Journal of Pharmaceutics, Vol. 203, No. 1-2, 2000, pp.179-192. doi:10.1016/S0378-5173(00)00444-0

[12] M. M. Talukdar, V. D. Mooter, P. Augustijns, T. T. Maga, N. Verbeke and R. Kinget, "In Vitro Evaluation of Xanthan Gum as a Potential Excipient for Oral Controlled Release Matrix Tablet Formulation,” International Journal of Pharmaceutics, Vol. 169, No. 1, 1998, pp. 105-113. doi:10.1016/S0378-5173(98)00112-4

[13] K. Watanabe, S. Yakou, K. Takayama, Y. Machida, K. Isowa and T. Nagai, "Investigation on Rectal Absorption of Indomethacin from Sustained-Release Hydrogel Suppositories Prepared with Water-Soluble Dietary Fibers, Xanthan Gum and Locust Bean Gum,” Biological and Pharmaceutical Bulletin, Vol. 16, No. 4, 1993, pp. 391394. doi:10.1248/bpb.16.391

[14] K. Watanabe, S. Yakou, K. Takayama, Y. Machida and T. Nagai, "Factors Affecting Prednisolone Release from Hydrogels Prepared with Water-Soluble Dietary Fibers, Xanthan and Locust Bean Gums," Chemical and Pharmaceutical Bulletin, Vol. 40, No. 2, 1992, pp. 459-462. doi:10.1248/cpb.40.459

[15] A. Korner, A. Larsson, L. Piculell and B. Wittgren, “Tunning the Polymer Release from Hydrophilic Matrix Tablets by Mixing Short and Long Matrix Polymers," International Journal of Pharmaceutics, Vol. 94, No. 4, 2005, pp. 759-769.

[16] L. Yang, G. Venkatesh and R. Fassihi, “Characterization of Compressibility and Compactibility of Poly(Ethylene Oxide) Polymers for Modified Release Application by Compaction Simulator," International Journal of Pharmaceutics, Vol. 85, No. 5, 1996, pp. 1085-1090.

[17] C. J. Kim, "Drug Release from Compressed Hydrophilic POLYOX-WSR Tablets,” International Journal of Pharmaceutics, Vol. 84, No. 3, 1995, pp. 303-306.

[18] M. Efentakis and M. Vlachou, "Evaluation of High Mo- 
lecular Weight Poly(oxyethylene) (Polyox) Polymer: Studies of Flow Properties and Release Rate of Furosemide and Captopril from Controlled Release Hard Gelatin Capsules," Pharmaceutical Development and Technology, Vol. 5, No. 3, 2005, pp. 339-348. doi:10.1081/PDT-100100549

[19] L. Maggi, R. Bruni and U. Conte, "High Molecular Weight Polyethylene Oxides (PEOs) as an Alternative to HPMC in Controlled Release Dosage Forms,” International Journal of Pharmaceutics, Vol. 195, No. 1-2, 2000, pp. 229-238.

[20] S. J. Jin, Y. H. Yoo, M. S. Kim, J. S. Kim, J. S. Park and S. J. Hwang, "Paroxetine Hydrochloride Controlled Release POLYOX ${ }^{\circledR}$ Matrix Tablets: Screening of Formulation Variables Using Plackett-Burman Screening Design,” Pharmaceutical Research, Vol. 31, No. 3, 2008, pp. 339405.

[21] N. T. Weiss, L. Jones and J. C. Chamberlain, “A Possible Case of Venlafaxine-Induced Stevens-Johnson Syndrome,” Journal of Clinical Psychiatry, Vol. 65, No. 10, 2004, pp. 1431-1433. doi:10.4088/JCP.v65n1020d

[22] J. S. Olver, G. D. Burrows, T. R. Norman, “The Treatment of Depression with Different Formulations of Venlafaxine: A Comparative Analysis,” Human Psychopharmacology, Vol. 19, No. 1, 2004, pp. 9-16. doi:10.1002/hup.551

[23] P. Costa, "An Alternative Method to the Evaluation of Similarity Factor in Dissolution Testing," International Journal of Pharmaceutics, Vol. 220, No. 1-2, 2001, pp. 77-83. doi:10.1016/S0378-5173(01)00651-2

[24] T. Higuchi, "Mechanisms of Sustained-Action Medication: Theoretical Analysis of Rate of Release of Solid Drugs Dispersed in Solid Matrices," Journal of Pharmaceutical Science, Vol. 54, No. 12, 1963, pp. 1145-1149. doi:10.1002/jps.2600521210

[25] G. Ertan, H. Y. Karasulu, E. Karasulu, M. A. Ege, T. Kose and T. Guneri, "A New in Vitro/in Vivo Kinetic Correlation Method for Nitrofurantoin Matrix Tablet Formulations," Drug Development of Industrial Pharmacy, Vol. 26, No. 7, 2000, pp. 737-743. doi:10.1081/DDC-100101292

[26] M. C. Gohel and S. H. Bariya, “Advanced Formulation Design of Venlafaxine Hydrochloride Coated and TripleLayer Tablets Containing Hypromellose," Pharmaceutical Development and Technology, Vol. 14, No. 6, 2009, pp. 650-658. doi:10.3109/10837450902911911

[27] M. C. Gohel, R. K. Parikh, M. N. Padshala, K. G. Sarvaiya and D. G. Jena, "Formulation and Optimization of Directly Compressible Isoniazid Modified Release Matrix Tablet,” Indian Journal of Pharmaceutical Science, Vol. 69, No. 5, 2007, pp. 640-645. doi:10.4103/0250-474X.38468

[28] M. Bamba, F. Puisievx, J. P. Marty and J. T. Carstensen, "Release Mechanism in Gel Forming Sustained Release Formulations," International Journal of Pharmaceutics, Vol. 2, No. 5-6, 1979, pp. 307-311. doi:10.1016/0378-5173(79)90037-1

[29] D. S. Roy and B. D. Rohera, "Comparative Evaluation of Rate of Hydration and Matrix Erosion of HEC and HPC and Study of Drug Release from Their Matrices,” European Journal Pharmaceutical Science, Vol. 16, No. 3, 2002, pp. 193-199. doi:10.1016/S0928-0987(02)00103-3

[30] V. P. Shah, Y. Tsong, P. Sathe and J. P. Liu, "In Vitro Dissolution Profile Comparison-Statistics and Analysis of the Similarity Factor $f_{2}$," Pharmaceutical Research, Vol. 15, No. 6, 1998, pp. 889-896. doi:10.1023/A:1011976615750

[31] U. Conte, L. Meggi, P. Colombo, M. A. La, "Multilayered Hydrophilic Matrices as Constant Release Devices (Geomatrix $^{\mathrm{TM}}$ Systems)," Journal of Control Release, Vol. 26, No. 1, 1993, pp. 39-47. doi:10.1016/0168-3659(93)90207-L

[32] M. A. El-Nabarawi, "Modulation of Tenoxicam Release from Hydrophilic Matrix: Modulator Membrane versus Rate-Controlling Membrane,” Chemical and Pharmaceutical Bulletin, Vol. 53, No. 9, 2005, pp. 1083-1087. doi:10.1248/cpb.53.1083

[33] FDA Alert for Healthcare Professionals, "Hydromorphone Hydrochloride Extended-Release Capsules (Marketed as Palladone ${ }^{\mathrm{TM}}$ )," 2005.

http://www.fda.gov/cder/drug/InfoSheets/HCP/hydromor phoneHCP.pdf http://www.fda.gov

[34] M. J. Traynor, M. B. Brown, A. Pannala, P. Beck and G. P. Martin, "Influence of Alcohol on the Release of Tramadol from 24-h Controlled-Release Formulations during in Vitro Dissolution Experiments," Drug Development and Industrial Pharmacy, Vol. 34, No. 8, 2008, pp. 885889. doi:10.1080/03639040801929240 